\section{Commentary: Methods in observational studies in valve surgery, when time matters}

\author{
Mario F. L. Gaudino, MD, $\mathrm{PhD},{ }^{\mathrm{a}}$ and \\ Cristiano Spadaccio, $\mathrm{MD}, \mathrm{PhD}^{\mathrm{b}, \mathrm{c}}$
}

In this issue of the Journal, Kim and colleagues ${ }^{1}$ provide insightful information on the fate of the aortic valve in patients with rheumatic disease undergoing surgery of the mitral valve. Their main finding is that progression of aortic valve disease and the need for aortic valve replacement are relatively uncommon in these patients, with the risk correlated with the severity of the aortic valve dysfunction at the time of the mitral operation.

This study gives us a real-life picture of rheumatic disease from a large institutional database from areas with high prevalence of this condition. Despite the limitations inherent to the retrospective nature of the study, the findings are hypothesis-generating and open to interesting clinical and methodological reflections.

A commonly encountered problem in the surgical literature is the lack of systematic follow-up. In particular, imaging follow-up with angiography or echocardiography tends to be fragmentary and incomplete across surgical series, and thus in many instances, it impedes a clear picture of the durability of a procedure or the evolution of a disease condition.

When exploring long-term, temporally driven outcomes of surgical procedures in retrospective studies, longitudinal analyses are key to defining trends in the natural history of diseases and in identifying prognostic factors. ${ }^{2}$ In valve surgery, the lessons learned by trials comparing surgical valve replacement with transcatheter technologies have promoted

From the ${ }^{\mathrm{a} D e p a r t m e n t}$ of Cardiothoracic Surgery, New York Presbyterian/ Weill Cornell Medical Center, New York, NY; 'bepartment of Cardiothoracic Surgery, Lancashire Cardiac Center, Blackpool Victoria Hospital, Blackpool, United Kingdom; and ${ }^{c}$ University of Glasgow Institute of Cardiovascular and Medical Sciences, Glasgow, United Kingdom.

Disclosures: The authors reported no conflicts of interest.

The Journal policy requires editors and reviewers to disclose conflicts of interest and to decline handling or reviewing manuscripts for which they may have a conflict of interest. The editors and reviewers of this article have no conflicts of interest.

Received for publication March 23, 2021; revisions received March 23, 2021; accepted for publication March 23, 2021; available ahead of print March 30, 2021.

Address for reprints: Mario F. L. Gaudino, MD, PhD, Department of Cardiothoracic Surgery, Weill Cornell Medicine, New York-Presbyterian Hospital, 525 E 68th St,

New York, NY 10021 (E-mail: mfg9004@med.cornell.edu).

J Thorac Cardiovasc Surg 2023;165:632-3

0022-5223/\$36.00

Copyright (c) 2021 by The American Association for Thoracic Surgery

https://doi.org/10.1016/j.jtcvs.2021.03.082

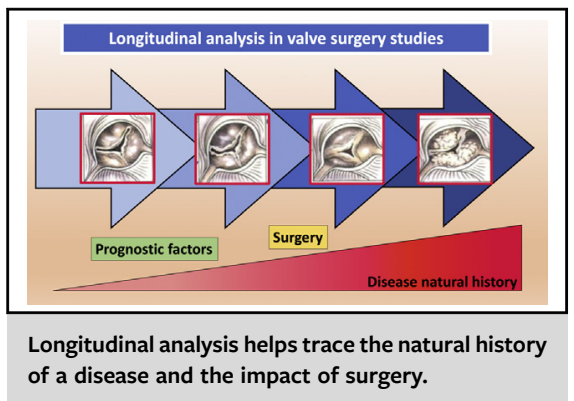

CENTRAL MESSAGE

Systematic longitudinal followup is generally missing in surgical studies. Longitudinal long-term analyses are needed to define the natural history of diseases and identify prognostic factors.

surgeons' awareness of the importance of robust follow-up analysis. In trials of both transcatheter aortic and mitral valve implantation, rigorous long-term follow-up is performed according to standardized criteria, providing an opportunity for surgical valvular procedures to be subjected to the same level of scrutiny.

The surgical community has not put enough effort into analyzing the results in other fields. Longitudinal analyses are valuable tools to temporally describe the natural history of diseases and to assess whether a particular procedure is able to influence it. As an example, the long-term outcomes of bicuspid aortic valve repair ${ }^{3}$ and of the Ross procedure ${ }^{4}$ have recently been analyzed with linear mixed-effects modeling, providing a detailed temporal trajectory of the results of these interventions.

Another important advantage of longitudinal models is the possibility of identifying subgroups of patients at increased risk of developing complications or having accelerated progression of disease, with the aim of implementing surveillance programs. In fact, clinical or anatomic predictors found at the temporal analysis could be used to distinguish disease "phenotypes" with differing tendencies to develop particular outcomes. A similar approach has been adopted in bicuspid valve aortopathy. ${ }^{5}$ The results of the work of Kim and colleagues could open the way to similar conceptualizations for mitral pathology and better inform the identification of subjects more prone to develop the effects of the progression of the underlying disease over time. These subsets of patients 
might merit a more individualized treatment strategy or prophylactic surgical interventions.

\section{References}

1. Kim HR, Kim WK, Kim HJ, Kim JB, Jung SH, Choo SJ, et al. The fate of aortic valve after rheumatic mitral valve surgery. J Thorac Cardiovasc Surg. 2023;165: 622-9.e2.

2. Gibbons RD, Hedeker D, DuToit S. Advances in analysis of longitudinal data. Annu Rev Clin Psychol. 2010;6:79-107.
3. Schneider U, Hofmann C, Schöpe J, Niewald AK, Giebels C, Karliova I, et al Long-term results of differentiated anatomic reconstruction of bicuspid aortic valves. JAMA Cardiol. 2020;5:1-8.

4. Romeo JLR, Papageorgiou G, da Costa FFD, Sievers HH, Bogers AJJC, ElHamamsy I, et al. Long-term clinical and echocardiographic outcomes in young and middle-aged adults undergoing the Ross procedure. JAMA Cardiol. March 3, 2021 [Epub ahead of print].

5. Della Corte A, Bancone C, Quarto C, Dialetto G, Covino FE, Scardone M, et al Predictors of ascending aortic dilatation with bicuspid aortic valve: a wide spectrum of disease expression. Eur J Cardiothorac Surg. 2007;31:397-404; discussion 404-5. 